\title{
ESTUDIO PRELIMINAR DE LA VARIABILIDAD INTRAESPECÍFICA DE PROTEÍNAS SEMINALES EN Araujia hortorum FOURN (Apocynaceae).
}

\section{PRELIMINAR STUDY OF THE INTRASPECIFIC VARIABILITY OF SEED PROTEINS IN Araujia hortorum FOURN (Apocynaceae)}

\author{
Gonzales Medrano, M.F. ${ }^{a}$, Galvez, M.J. ${ }^{\text {, }}$ González, S.R. ${ }^{b}$ y Villamil, C.B. ${ }^{b}$
}

\section{RESUMEN}

Araujia hortorum Fourn es una enredadera perenne sudamericana que se comporta como invasora en cultivos y en áreas de reserva natural. Han habido controversias sobre la conveniencia de considerarla como especie independiente o como entidad infraespecífica subordinada a A. sericifera Brot. (Araujia sericifera $f$. hortorum Malme). Como criterio complementario para definir esta situación se han comparado muestras de semillas provenientes de nueve poblaciones de la región pampeana argentina ( $A$. cf. hortorum) y una coleccionada en la selva misionera $(A$. cf. sericifera). Mediante la utilización de los métodos de electroforesis en gel de poliacrilamida (PAGE-SDS) y de inmunotransferencia (IT, "immunoblotting") se ha podido detectar la presencia de 19 y 18 bandas proteicas respectivamente, aunque no coincidentes entre sí. La utilización del Índice de Jaccard arrojó valores de similitud entre 0.39-1.00 y 0.53-1.00 respectivamente. Las diferencias encontradas deben atribuirse, en parte, a la dificultad para determinar la presencia o ausencia de algunas de las bandas de menor intensidad. La población misionera mostró menor similitud con las pampeanas que éstas entre sí. Los resultados obtenidos demuestran una considerable uniformidad genética entre ambas entidades putativas, lo que sugiere la necesidad de comparar poblaciones adicionales de ambas para evaluar más objetivamente la consistencia de estos métodos en su caracterización sistemática.

Palabras clave: Inmunotransferencia, Araujia, proteínas seminales, Apocynaceae

\section{ABSTRACT}

Araujia hortorum Fourn is a sudamerican perennial climbing plant that performs like an invasive in crops and natural reserve areas. There have been controversies about to consider it as independent specie or like an intraspecific entity dependent to $A$. sericifera Brot. (Araujia sericifera $f$. hortorum Malme). As a complement approach to define its situation, It has been compared some seeds samples coming from nine populations from Argentina's pampean region ( $A$. cf. hortorum) and another from Misionera jungle ( $A$. cf. sericifera). through use the method of polyacrylamide gel electrophoresis (PAGE-SDS) and immnunoblot assay (IT, "immunoblotting"), it have been able to detect the presence of 19 and 18 protein bands respectively, although they are not coincident to each other. The use of the Jaccard Index shows values of similarity among $0.39-1.00$ and $0.53-1.00$, respectively. Differences should be attributed, partly, to the difficulty to determine the presence or absence of some of the bands of small intensity. The population from Misionera jungle showed smaller similarity with the pampeans that between each other. The results realized a considerable genetic uniformity among both putative entities that suggests the necessity to compare both additional populations in order to evaluate the consistency of these methods more objectively in their systematic characterization.

Key words: Immunoblotting, Araujia, seeds proteins, Apocynaceae.

\section{INTRODUCCIÓN}

Brown, reconoció en 1810 a Asclepiadaceae como una familia nueva, separada de Apocynaceae; sin embargo, se ha presentado mucha controversia evaluando su relación respecto a la familia Apocynaceae (1). La utilización de análisis filogenéticos a nivel molecular ha apoyado su inclusión dentro de la familia Apocynaceae $(2,3)$. Dentro de esta se describe el género Araujia, especie nativa del Brasil meridional, registrada como una planta invasiva en Sudáfrica y Nueva Zelanda. Araujia hortorum ha presentado confusiones en su taxonomía debido a que muchos especimenes han sido descritos como $A$. sericífera. Dentro del género se han presentado confusiones taxonómicas entre Araujia hortorum y Araujia sericifera, aunque Forster y Buyrns indican se trata de sinónimos (4). Al comparar relaciones taxonómicas en vegetales, la taxonomía se apoya en la utilización de métodos morfológicos, embriológicos, ecológicos, análisis palinológicos además de los análisis moleculares que están siendo utilizados para ofrecernos una herramienta complementaria en la identificación de entidades vegetales. Anteriormente se demostró un mayor poder resolutivo de la Inmunotransferencia en relación con la técnica de inmunodifusión bidimensional y su mayor precisión al utilizarse en serotaxonomía vegetal en comparación con el método de Outcherlony $(5,6)$. El objetivo del presente estudio es evaluar la similitud existente entre los perfiles proteicos de ambas entidades vegetales utilizando el método de Inmunotransferencia.

\section{MATERIALES Y MÉTODOS}

\section{Material Vegetal}

Para la preparación de los extractos proteicos se utilizaron muestras de semillas indicadas en la Tabla 1

aUniversidad Nacional Agraria La Molina, Lima, Perú

${ }^{\mathrm{b}}$ Departamento de Biología, Bioquímica y Farmacia, Universidad Nacional del Sur, Bahía Blanca, Argentina. 


\section{Material Animal}

Se utilizaron 4 conejos Nueva Zelanda sanos de $2 \frac{1}{2}$ meses de edad con pesos de alrededor $2500 \mathrm{~g}$ cada uno mantenidos en el Bioterio de la Universidad Nacional del Sur.

\section{Preparación de los antígenos.}

Se pesó una muestra de $1 \mathrm{~g}$ de semillas de cada población de Araujia colectada. Las semillas fueron molidas en un molino Braun KSM 2 durante 30 segundos, separadas en repeticiones de 10 segundos por cada una. Se delipificó cada muestra de las semillas con 9 lavados sucesivos en los cuales se agregó $5 \mathrm{ml}$ de éter de petróleo y se resuspendió en un VORTEX standard FAC durante $30 \mathrm{~s}$. Se reposaron durante 20 minutos y luego se eliminó el sobrenadante obtenido por centrifugación en centrífuga GELEC GL40 a 1500 RPM durante 10 minutos. Durante el tercer enjuague el tiempo de reposo fue de 20 horas. Se determinó la ausencia de lípidos con la desaparición de rastros oleosos sobre papel filtro.

Las muestras secas obtenidas posteriores a la molienda fueron lavadas con acetona y tamizadas a través de una rejilla de número $35.100 \mathrm{mg}$ de cada muestra fueron resuspendidos en $900 \mu \mathrm{l}$ de buffer de extracción y se dejó reposar durante 11 horas. Los sobrenadantes fueron centrifugados a 12000 RPM durante 10 minutos. Se tomaron $100 \mu \mathrm{l}$ del sobrenadante y se mezclaron con buffer (Tris- $\mathrm{HCl} \quad 0,125 \mathrm{M}$ pH 6,8; SDS 4\%; 2 Mercaptoetanol $10 \%$; Sacarosa $20 \%$ y Azul de bromofenol $0,002 \%$ ) y se llevaron a hervir por 3 minutos.

\begin{tabular}{|c|c|c|}
\hline Especie & Localidad, Provincia, Pais & Año de colección \\
\hline 1 Araujia cf horforum & Tres Arroyos, Buenos Aires, Argentina & 2004 \\
\hline 2 Araujia cf hortorum & LLa Plata, Buenos Aires, Argentina & 2004 \\
\hline 3 Araujia cf hotorum & Punta Indio, Buenos Aires, Argentina & 2004 \\
\hline 4 Araujia cf hortorum & Castelli, Buenos Aires, Argentina & 2004 \\
\hline 5 Araujia cf hortorum & Casilda, Santa Fe, Argentina & 2004 \\
\hline 6 Araujia cf hortorum & Zavalla, Santa Fe, Argentina & 2004 \\
\hline 7 Araujia cf hortorum & Chovet, Santa Fe, Argentina & 2004 \\
\hline 8 Araujia cf hortorum & Murphy, Santa Fe, Argentina & 2004 \\
\hline 9 Araujia cf hortorum & Bahía Blanca, Buenos Aires, Argentina & 2004 \\
\hline 10 Araujia cf hotorum & San José, Misiones, Argentina & 2006 \\
\hline
\end{tabular}

Tabla 1: Muestras de semillas empleadas para la comparación de las proteínas seminales de diez poblaciones de Araujia.

\section{Preparación de los antisueros.}

Los extractos antigénicos obtenidos fueron mezclados en proporción (1:2) con adyuvante de Freund compuesto. Subcutáneamente se inoculó $0.375 \mathrm{ml}$ en cada lado del la columna vertebral. El programa de inoculación fue de 7 inoculaciones, con 4 días de separación entre cada una. Debido al significativo crecimiento de los granulomas la sexta inoculación se hizo con Adyuvante de Freund incompleto y la sétima sin adyuvante. Se realizó una sangría exploratoria, se dejó coagular por 2 horas a temperatura ambiente $y$ fueron conservados en refrigeración por 24 horas. Posteriormente, los sueros fueron separados por centrifugación a $1500 \mathrm{rpm}$ por 10 minutos. Se detectó una alta presencia de anticuerpos específicos utilizando el método de precipitación zonal rápida en medio líquido ("Ring Test").

\section{Electroforesis PAGE.}

El método de SDS-PAGE fue utilizado para la separación de los fragmentos proteicos purificados sobre un gel de poliacrilamida con el agregado de dodecilsulfato de sodio, Esta técnica ha demostrado una gran potencialidad en la identificación de polimorfismos dentro de cultivos vegetales (7). Se utilizó un equipo Hoefer Mighty Small SE 245-Dual Gel Caster para realizar la corrida en PAGE vertical (8). El gel de resolución fue vertido sobre el soporte eliminando las burbujas con agua destilada. Después gelificado, se completó con el gel de stacking formando los pocillos de corrida con la utilización de un peine. Posteriormente se continuó con la metodología descrita por Margni et al (9), sembrándose $20 \mu \mathrm{l}$ de las muestras en el orden descrito por la tabla 1. Las condiciones de corrida fueron 90 v., $44 \mathrm{~mA}$. por $4 \mathrm{H} \mathrm{50}$ '. El gel fue enjuagado en una solución fijadora por espacio de 1 hora. Se coloreó con una solución de $2 \mathrm{~g}$ de Negro amido por cada $1000 \mathrm{ml}$ de ácido acético al $7 \%$ durante 2 horas y se enjuagó con ácido acético al $7 \%$ hasta decolorar completamente (Figura 1).
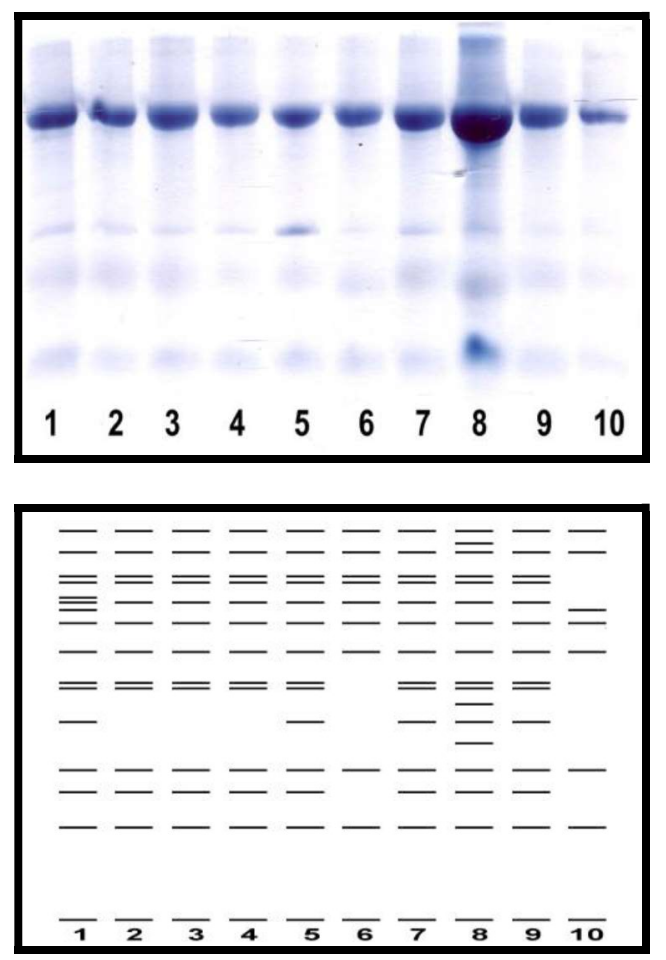

Figura 1. Diez poblaciones de Araujia analizadas por PAGE-SDS (ver Tabla 1) y diagrama interpretativo correspondiente.

\section{Inmunotransferencia.}

Se realizó electroforesis en PAGE vertical como la descrita previamente, invirtiendo el orden de siembra y diluyendo al cuarto la muestra de S-227 para su mejor identificación, sembrándose $12.5 \mu \mathrm{l}$ de ésta y $20 \mu \mathrm{l}$ de las 9 restantes aumentándose la densidad con una pizca de sucrosa. Las condiciones de corrida fueron de 90 v., 44 $\mathrm{mA}$. durante 5 horas con 35 minutos .

Se embebieron en buffer de transferencia con la finalidad de remover sales y detergentes del buffer de corrida del gel y el cassette para la transferencia de las proteínas a membrana de nitrocelulosa fue armado según la metodología descrita por Margni et al (9), eliminando las burbujas que puedan formarse entre cada capa. Se ubicó 
el gel hacia el polo negativo y la membrana hacia el polo positivo. Las condiciones de corrida fueron de 75 v., 350 $\mathrm{mA}$ durante 1 hora con 30 minutos. La transferencia fue corroborada tiñendo la membrana con Rojo Ponceau por 3 minutos y decolorándola con agua destilada. Se realizó el bloqueo de las regiones con ausencia de proteínas embebiendo con una solución proteica TBS-L de $250 \mathrm{mg}$ de leche en polvo descremada MOLICO en $50 \mathrm{ml}$ de TBS durante 14 horas y 30 minutos. Se realizaron lavados sucesivos con TBS durante 6 horas.

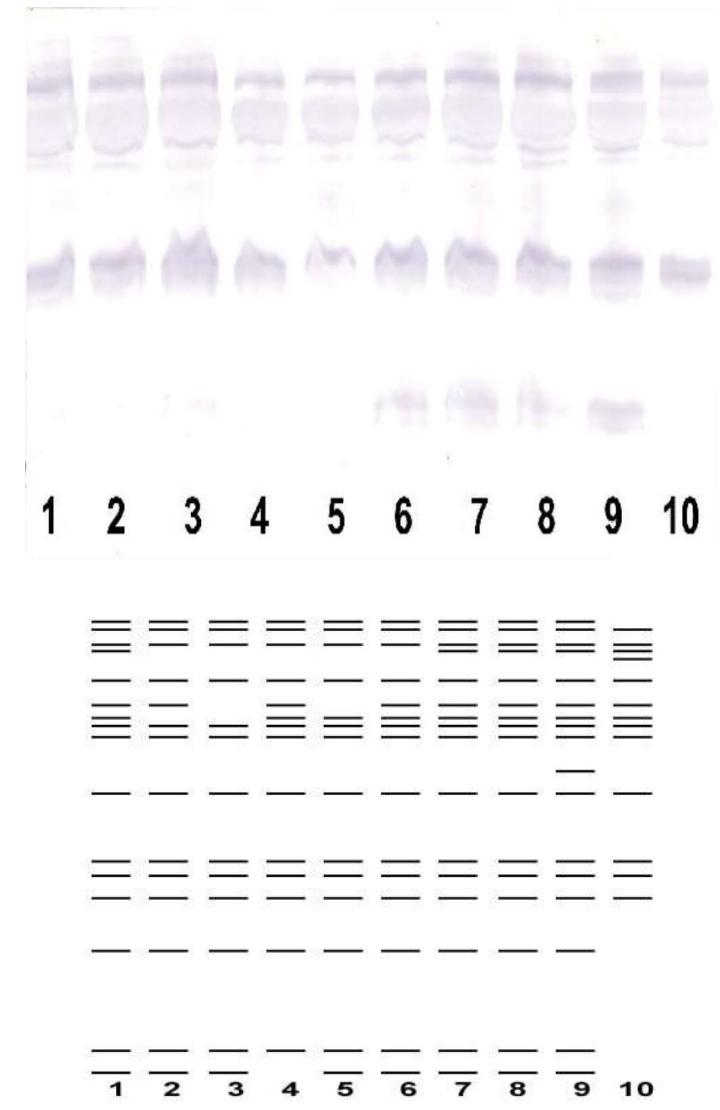

Figura 2. Diez poblaciones de Araujia analizadas por IT (ver Tabla 1) y diagrama interpretativo correspondiente.

Se incubó el anticuerpo específico obtenido en conejos en proporción 1:100 en $50 \mathrm{ml}$ de solución TBS-L sobre la membrana durante 1 hora y 30 minutos. Se realizaron 4 lavados cortos sucesivos con TBS, un lavado de 15 horas y lavados sucesivos por 6 horas más.

Se incubó $30 \mu \mathrm{l}$ de anti-gamma-globulina conjugada en 9 $\mathrm{ml}$ de TBS-L cubriendo la región de la membrana de nuestro interés por espacio de 1 hora y 30 minutos. Se realizaron 7 lavados cortos sucesivos, un lavado de 13 horas y lavados continuos por 2 horas.

Se disolvieron $30 \mathrm{mg}$ de 4-Cloro-1-naftol en $10 \mathrm{ml}$ de metanol, en oscuridad, y se combinó con $\mathrm{H}_{2} \mathrm{O}_{2}$ de 30 volúmenes en $50 \mathrm{ml}$ de TBS. Se sumergió la membrana sobre la solución, dejando actuar por 18 minutos en oscuridad, hasta observar el revelado (Figura 2).

\section{RESULTADOS}

Se detectó un máximo de 19 bandas con variable intensidad en gel de PAGE-SDS. Los perfiles proteicos de las semillas evaluadas, mostraron una gran similitud entre si (Fig. 1). La similitud fue medida a través del coeficiente de Jaccard, obteniendo rangos de $59 \%$ al $100 \%$ para las muestras del 1 al 9 . La muestra 10 generó coeficientes de Jaccard con rangos entre $39 \%$ a $64 \%$ de similitud con las demás. Un dendrograma fue construido con los valores obtenidos mediante el método de agrupamiento de UPGMA (unweighted pair-group method using arithmetic averages) analizados con el programa informático NUCOSA v. 1.05.

Con la prueba de Western Blot se obtuvieron resultados cualitativos similares, con un total de 19 bandas con variable intensidad y mayor definición. Se obtuvo una gran similitud de bandas entre las poblaciones de Araujia hortorum y una ligera diferencia de bandas de la muestra 10 con respecto a las demás muestras pampeanas. Los índices de similitud variaron entre 0.53 y 1.00 (Tabla 2) y se construyó un dendrograma para estos resultados mediante el método de UPGMA (Figura 3).

\begin{tabular}{|l|l|l|l|l|l|l|l|l|l|l|}
\hline 1 & 1 & 2 & 3 & 4 & 5 & 6 & 7 & 8 & 9 & 10 \\
\hline 2 & 1.00 & & & & & & & & & \\
\hline 3 & 0.88 & 1.00 & & & & & & & & \\
\hline 4 & 0.81 & 0.93 & 1.00 & & & & & & & \\
\hline 5 & 0.88 & 0.87 & 0.80 & 1.00 & & & & & & \\
\hline 6 & 0.94 & 0.93 & 0.83 & 0.87 & 1.00 & & & & & \\
\hline 7 & 1.00 & 0.88 & 0.81 & 0.93 & 0.93 & 1.00 & & & & \\
\hline 8 & 0.94 & 0.93 & 0.87 & 0.81 & 0.88 & 0.94 & 1.00 & & & \\
\hline 9 & 0.94 & 0.82 & 0.76 & 0.82 & 0.82 & 0.88 & 0.94 & 1.00 & & \\
\hline 10 & 0.71 & 0.59 & 0.53 & 0.69 & 0.59 & 0.65 & 0.71 & 0.65 & 0.67 & 1.00 \\
\hline
\end{tabular}

Tabla 2. Matriz de similitud (índice de Jaccard) calculada a partir de los resultados de IT (Figura 2 ).

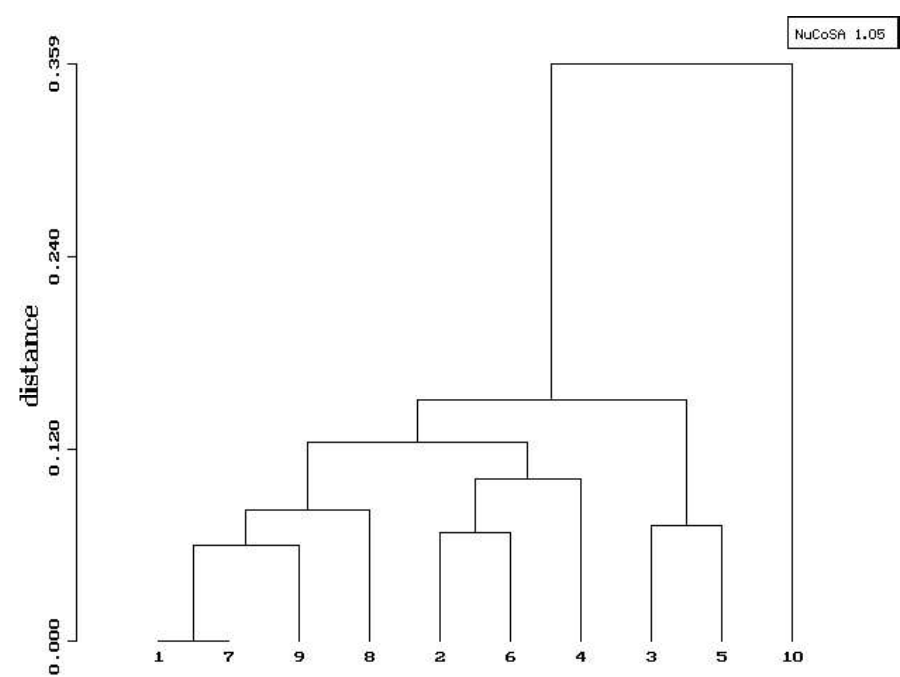

Figura 3. Dendrograma (UPGMA) correspondiente a los resultados obtenidos por IT (Figura 2 y Tabla 2 ).

\section{DISCUSIONES}

Las proteínas seminales de Araujia han demostrado ser un material apropiado para estudios comparativos utilizando métodos electroforéticos e inmunológicos, ya que presentan epítopos capaces de generar respuestas inmunogénicas en animales de laboratorio.

El método de inmunotransferencia, por la especificidad de unión a los antígenos proteicos incrementando su intensidad, presentó un mejor perfil en la evaluación de polimorfismos por presencia o ausencia de bandas. Los espectros obtenidos en ambos métodos señalan una considerable uniformidad en la composición proteica de todas las muestras estudiadas, similar a la hallada por 
Castro et al (10). Las diferencias detectadas corresponden en todos los casos a bandas débiles o de difícil percepción.

En los análisis de agrupamiento resultantes de la aplicación de ambos métodos la población de Misiones ( $N^{\circ}$ 10, Araujia cf. sericifera) aparentemente se separa de las poblaciones pampeanas $\left(\mathrm{N}^{\circ} 1\right.$ a 9 , Araujia $c f$ hortorum).

Estos resultados preliminares sugieren que podrían existir diferencias en la composición proteica entre ambas entidades sistemáticas, los cuales deberían confirmarse con la inclusión de un mayor número de muestras.

\section{REFERENCIAS BIBLIOGRAFICAS}

[1]. Brown R. On the Asclepiadaceae, a natural order of plants separated from the Apocyneae of Jussieu. Memoirs of the Wer- nerian Natural History Society. 1810; 1:12-787.

[2]. Judd W., Sanders R., Donoghüe M. Angiosperm family pairs: Preliminary phylogenetic analyses. Harvard Papers in Botany. 1994; 1(5):1-51.

[3]. Civeyrel L., Le Thomas A., Ferguson K., Chase M. Critical Reexamination of Palynological Characters Used to Delimit Asclepiadaceae in Comparison to the Molecular Phylogeny Obtained from PastidmatK Sequences. Molecular Phylogenetics and Evolution. 1998; 9(3):517-527.

[4]. Forster P., Bruyns P. Clarification of Synonymy for the Common Moth-Vine Araujia sericifera (Asclepiadaceae). Taxon. 1992; 41(4):746-749.

[5]. Castro H., González S., Prat M., Villamil C. Utilización del método de inmunotransferencia ("Western blotting") en taxonomía vegetal. Phiton. 1999; 65:185-196.

[6]. Marcone M., Kakuda Y., Yada R. Immunochemical examination of the surface physico-chemical properties of various dictyledonous and monocotyledonous globulin seed storage proteins. Food Chemistry. 1998; 63(1):85-95.

[7]. Cooke R. Gel electrophoresis for the identification of plant varietis. Journal of chromatografy A. 1995; 698:281299.

[8]. Towbin H., Staehelin T., Gordon J. Electrophoretic transfer of proteins from polyacrilamide gels to nitrocellulose sheets: Procedure and some applications. Proceedings of the National Academy of Sciences of the United States of America. 1979; 76(9): 4350-4354.

[9]. Margni RA, Malchiodi EL, Charamonte MG. Electroforesis en gel de poliacrilamida; Inmunotransferencia (immunoblotting); Apéndice I. In RA Margni (ed.). Inmunología e Inmunoquímica. $5^{\text {a }}$ ed. Editorial Médica Panamericana. Argentina. 1996.

[10]. Castro H., Galvez M., González S., Villamil C. Protein composition of Cucúrbita maxima and C. moschata seeds. Biología Plantarum. 2006; 50(2):251-256.

E-mail: fgonzalesm@gmail.com 